\title{
Inpatient Cost of Stroke Care in Greece: Preliminary Results of the Web-Based "SUN4P" Registry
}

Olga SISKOU ${ }^{\mathrm{a}, 1}$, Petros GALANIS ${ }^{\text {a }}$, Olympia KONSTANTAKOPOULOU ${ }^{\text {a }}$, Iliana

KARAGKOUNI $^{\mathrm{a}}$, Evangelos TSAMPALAS ${ }^{\mathrm{b}}$, Dafni GAREFOU ${ }^{\mathrm{b}}$, Helen

ALEXOPOULOU $^{\mathrm{b}}$, Anastasia GAMVROULA ${ }^{\mathrm{b}}$, Ioannis KALLIONTZAKIS ${ }^{\mathrm{c}}$, Anastasia FRAGKOULAKI ${ }^{\mathrm{c}}$, Aspasia KOURIDAKI ${ }^{\mathrm{c}}$, Argyro TOUNTOPOULOU ${ }^{\mathrm{d}}$,

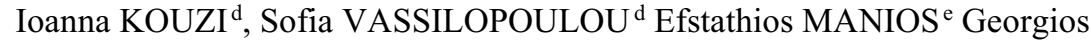
MAVRAGANIS $^{\mathrm{e}}$, George NTAIOS ${ }^{\mathrm{f}, \mathrm{g}}$, Efstathia KARAGKIOZI ${ }^{\mathrm{g}}$, Anna Maria LOUKA $^{\mathrm{g}}$, Christos SAVOPOULOS ${ }^{\mathrm{h}}$ Gregorios DIMAS $^{\mathrm{h}}$, Athina MYROU ${ }^{\mathrm{h}}$, Haralampos MILIONIS ${ }^{i}$, Georgios SIOPIS ${ }^{i}$, Hara EVAGGELOU ${ }^{i}$, Athanasios PROTOGEROU $^{\mathrm{j}}$, Stamatina SAMARA ${ }^{\mathrm{j}}$, Asteria KARAPIPERI ${ }^{\mathrm{j}}$, Nikolaos KAKALETSIS $^{\mathrm{k}}$, Paris GALLOS ${ }^{\mathrm{a}}$, Stefanos PAPASTEFANATOS ${ }^{\mathrm{a}}$, Panayota SOURTZI ${ }^{\mathrm{a}}$, Kostas VEMMOS ${ }^{\mathrm{f} *}$, Eleni KOROMPOK I ${ }^{\mathrm{e},{ }^{*}}$ and Daphne KAITELIDOU ${ }^{\mathrm{A}^{*}}$

*equal last authors

${ }^{a}$ Center for Health Services Management and Evaluation, Department of Nursing National and Kapodistrian University of Athens, Athens, Greece

${ }^{b}$ Department of Neurology, Panarkadikon General Hospital, Tripoli, Greece

${ }^{c}$ Department of Neurology, General Hospital of Chania, Creta, Greece

${ }^{d} 1$ st Department of Neurology, Eginition Hospital, National and Kapodistrian University of Athens, Athens, Greece

${ }^{e}$ Department of Clinical Therapeutics, Alexandra Hospital, National and Kapodistrian University of Athens, Athens, Greece

${ }^{f}$ Hellenic Stroke Organization, Greece

${ }^{g}$ Department of Internal Medicine, Faculty of Medicine, School of Health Sciences, University of Thessaly, Larissa, Greece

${ }^{h} 1$ st Medical Propedeutic Department of Internal Medicine, Aristotle University of Thessaloniki, AHEPA Hospital, Thessaloniki, Greece

${ }^{i}$ Department of Internal Medicine, School of Medicine, University of Ioannina, Ioannina, Greece

${ }^{\mathrm{j} C a r d i o v a s c u l a r}$ Prevention \& Research Unit in Laiko General Hospital of Athens at the Medical School of the National \& Kapodistrian University of Athens, Greece

${ }^{\mathrm{k}}$ Second Propedeutic Department of Internal Medicine, Aristotle University of

Thessaloniki, Hippokrateion General Hospital of Thessaloniki, Greece

\begin{abstract}
The aim of this study was to calculate the average operational cost per sub-type of stroke patient and to investigate cost drivers (e.g. ALoS, NIHSS score, age) correlated to cost. Methods: Direct medical costs (diagnostic imaging and clinical laboratory exams, overheads/bed cost, pharmaceuticals, ringers and other
\end{abstract}

\footnotetext{
${ }^{1}$ Corresponding author, Olga Siskou; E-mail: olsiskou@nurs.uoa.gr.
} 
non -durables and inpatient rehabilitation) per patient were calculated from the providers' (hospitals') perspective. Resource use data derived from the "SUN4P" web-based registry and unit costs were retrieved from publically available sources and were assigned to resource use. Results: The sample comprised 6,282 inpatient days of 750 patients (mean age: $75.5 \pm 13.3$ years) admitted from July 2019 to July 2021 , in nine public hospitals. Mean length of stay was $8.4 \pm 7.6$ days and mean total operational cost was calculated to $€ 1,239.4$ (from which $45 \%$ and $35 \%$ related to diagnostic exams and overheads/bed cost respectively). Mean cost related to hemorrhagic stroke patients that were discharged alive was calculated significantly higher compared to mean cost related to ischemic stroke patients who didn't undertake thrombolysis and were also discharged alive from the hospital $(€ 2,155.2$ vs. $€ 945.2, \mathrm{p}<0.001)$. Linear regression analysis revealed that length of stay was significantly correlated with cost (coefficient beta $=232$, 95\% CI confidence interval $=220-243, \mathrm{p}<0.001)$. Conclusions: These findings are in accordance with current evidence and should be thoroughly assessed to rationalize inpatient reimbursement rates in order to achieve improved value of care.

Keywords. Stroke, Mean Cost of Hospitalization Inpatient Stroke Care

\section{Introduction}

Stroke is a major public issue worldwide [1]. Effective management during acute phase (hospitalization) is associated with favorable outcomes, especially for patients suffering from ischemic stroke [2]. Notably, inpatient stroke care accounts for more than $70 \%$ of direct stroke health expenses over the cycle of care [3]. To date researchers calculate hospitalization costs by detailed sub-type of stroke [4]. However in Greece, hospitals' charges to National Organization for the Provision of Healthcare (EOPYY) are based on a kind of Diagnostic Related Groups /KEN-DRGs (Gazette 946/27/03/2012) where four generic tariffs (only for operational expenses, wages excluded) were set, without explicit description of diagnosis: a) N30A=€380 Stroke and other cerebral vessels disorders of a patient who died or was transferred to another hospital in less than 5 days from the admission b) N30X=€900 (Average Length of Stay $-A L o S=6$ ) Stroke and other cerebral vessels disorders without catastrophic or severe co-morbidities / complications c) $N 30 \mathrm{Mb}(A L O S=9)=€ 1,625$ Stroke and other cerebral vessels disorders with severe co-morbidities /complications d) N30Ma $(A L o S=17)=\epsilon 2,475$ Stroke and other cerebral vessels disorders with catastrophic or severe co-morbidities / complications. However, currently, Greek DRGs are under revision by the Hellenic Institution for DRGs. The aim of this study was to contribute to the efforts of policy makers to rationalize the reimbursement tariffs for inpatient stroke care. Thus, we calculated the average operational cost per sub-group of stroke patients and we investigated cost drivers (e.g. ALoS, NIHSS score, age) correlated to inpatient stroke cost.

\section{Methods}

Direct medical costs (diagnostic imaging and clinical laboratory exams, overheads/bed cost, pharmaceuticals included ringers and other non -durables and inpatient rehabilitation) per patient were calculated from the providers' (hospitals') perspective. Resource use data per patient derived from the "Improving Stroke Care in Greece in Terms of Management, Costs and Health Outcomes- (SUN4P)" web-based registry 
(ClinicalTrials.gov, NCT04109612) [5]. Unit costs, reflecting 2021 prices in euros, were retrieved from publically available sources (Ministry of Health, EOPYY, and National Organization for Drugs) and were assigned to resource use. Descriptive statistics (mean and median) were used in order to present average cost per group of patients and selected patients' characteristics. Student's t-test, ANOVA test, MannWhitney test, Kruskal-Wallis test, and Pearson's and Spearman's correlation coefficients were used for bivariate analyses. Finally, multivariate linear regression analysis was also performed with patient cost as the dependent variable and type of stroke, age, baseline NIHSS score and length of stay as independent variables. The SUN4P design was in accordance with the European General Data Protection Regulation (GDPR) and was aligned with the Declaration of Helsinki.

\section{Results}

The sample comprised 6,282 inpatient days of 750 patients (51.2\% males) admitted from July 2019 to July 2021 in nine public hospitals. Only 115 patients were hospitalized in a stroke unit while the majority of patients were admitted either in an internal medicine or in a neurological department. The vast majority of patients (91.5\%) underwent the first neuroimaging investigation (CT and/or MRI) during acute phase. In total 310 patients were administered antibiotics (mean cost $€ 350$, SD: 2,210) while only 32 patients (30 discharged alive) were administered thrombolysis (mean cost $€ 559.5$, SD: 112). Mean cost related to ischemic stroke patients who didn't undertake thrombolysis and were discharged alive was statistically significant lower compared to i) mean cost related to hemorrhagic stroke patients that were also discharged alive $(\mathrm{p}<0.001)$ and ii) mean cost related to ischemic stroke patients who didn't undertake thrombolysis and discharged died $(\mathrm{p}<0.009)$ (Table 1). Finally, linear regression analysis revealed that length of stay was significantly correlated with cost (coefficient beta $=232,95 \%$ CI confidence interval $=220-243, \mathrm{p}<0.001$ ).

Table 1. Baseline characteristics and average cost per sub group of stroke patients

\begin{tabular}{|c|c|c|c|c|c|c|}
\hline & $\begin{array}{c}\text { Ischemic stroke } \\
\text { without } \\
\text { Throbolysis- } \\
\text { Discharged } \\
\text { Alive (N=543) }\end{array}$ & $\begin{array}{c}\text { Ischemic } \\
\text { stroke without } \\
\text { Throbolysis- } \\
\text { Discharged } \\
\text { Died }(\mathbf{N}=53) \\
\end{array}$ & $\begin{array}{c}\text { Ischemic } \\
\text { stroke with } \\
\text { Throbolysis } \\
\text { Discharged } \\
\text { Alive }(\mathbf{N}=30)\end{array}$ & $\begin{array}{c}\text { Hemorrhagic } \\
\text { stroke - } \\
\text { Discharged } \\
\text { Alive }(\mathbf{N}=86)\end{array}$ & $\begin{array}{c}\text { Hemorrhagic } \\
\text { stroke - } \\
\text { Discharged } \\
\text { Died }(\mathbf{N}=36)\end{array}$ & $\begin{array}{l}\text { All Patients } \\
(\mathbf{N}=\mathbf{7 5 0})\end{array}$ \\
\hline Age* & $74.8(13.4)$ & $85.3(7.8)$ & $69.2(12.2)$ & $73.7(13.7)$ & $81.4(9.2)$ & $75.5(13.28)$ \\
\hline Baseline NIHSS** & $5(6)$ & $16(14.8)$ & $10(7.3)$ & $7(10.5)$ & $26.5(13)$ & $7(8)$ \\
\hline Baseline $\mathrm{mRS} * *$ & $0(1)$ & $1(4)$ & $0(0)$ & $0(1)$ & $0.5(1.8)$ & $0(1)$ \\
\hline \multirow[t]{2}{*}{ ALoS* } & $7.16(5.2)$ & $11.9(9.8)$ & $9.5(6.4)$ & $13.4(13.6)$ & $8.9(9.7)$ & $8.4(7.6)$ \\
\hline & $\begin{array}{l}945.2 \\
(652)\end{array}$ & $\begin{array}{c}\mathbf{1 , 9 5 7} \\
(1,833)\end{array}$ & $\begin{array}{l}\mathbf{1 , 8 5 0 . 4} \\
(729.1)\end{array}$ & $\begin{array}{c}\mathbf{2 , 1 5 5 . 2} \\
(5,453.2)\end{array}$ & $\begin{array}{c}\mathbf{1 , 8 9 7} \\
(3,118)\end{array}$ & $\begin{array}{l}\mathbf{1 , 2 3 9 . 4} \\
(2,150)\end{array}$ \\
\hline $\begin{array}{r}\text { Diagnostic Imaging } \\
\text { and Biochemical }\end{array}$ & & & & & & \\
\hline Exams & $504(301.2)$ & $758.3(543)$ & $617(232)$ & $689(625)$ & $633.5(685)$ & $554(402)$ \\
\hline $\begin{array}{l}\text { Bed/ Overheads } \\
\text { Pharmaceuticals }\end{array}$ & $364.5(311)$ & $656(660)$ & $585(485)$ & $703.6(768.5)$ & $478(596)$ & $439(458)$ \\
\hline $\begin{array}{r}\text { (included ringers and } \\
\text { other non durables) } \\
\text { Inpatient }\end{array}$ & $70.7(190.6)$ & $531.3(855)$ & $636(157)$ & $754.3(4,353)$ & $781(1,978.5)$ & $240(1,557)$ \\
\hline rehabilitation & $6(10.5)$ & $113(29.2)$ & $12(17.8)$ & $8.2(13)$ & $4.6(10)$ & $6.8(13.3)$ \\
\hline
\end{tabular}

NIHSS-National Institute for Stroke Scale;

mRS- modified Rankin Scale for Neurologic Disability / ALoS- Average Length of Stay in Days * Mean (SD) $/ * *$ Median (IQR) 


\section{Discussion}

Preliminary results of the SUN4P cohort demonstrate that mean hospitalization cost for the majority of the study patients, those with ischemic stroke who didn't undertake thrombolysis and were alive at the point of discharge, was almost equal to the relevant DRG N30X tariff referring to moderate severity stroke patients (€945 vs €900 /ALoS: 6 vs 7 days). However, as DRGs tariffs are not explicitly assigned with initial diagnosis by type of stroke and health status, misclassification to greater cost DRGs categories may potentially occur. Among inpatient stroke cost components, cost of diagnostic exams is prevalent congruent with previous studies from Greece [6],[7]. The overall mean cost in our study was calculated at less than half of the corresponding cost found in previous studies, as we didn't include wages cost. Those who died in hospital and those suffering from severe hemorrhagic stroke were found to incur remarkably higher total cost as compared to average cost of all patients, a finding that coincides with literature [8], as a result of increased utilization of resources during hospitalization.

\section{Conclusions}

The costs of inpatient stroke care vary greatly by type of stroke and diagnosis status. These findings demonstrates the necessity for revising the charging tariffs for inpatient stroke care in Greece, taken into consideration the initial explicit diagnosis and the hard outcomes at the point of discharge, and should be incorporated into cost effective strategies for improving value of provided care.

Acknowledgments: This project has received funding from the Hellenic Foundation for Research and Innovation (HFRI) and the General Secretariat for Research and Technology (GSRT), under grant agreement Nb538.

\section{References}

[1] Global Burden of Disease Data Base, 2017.

[2] Sousa D, Martial R, Abilleira RS, et al. Access to and delivery of acute ischemic stroke treatments: A survey of national scientific societies and stroke experts in 44 European countries. European Stroke Journal 2018;1: 13-28.

[3] European Cardiovascular Disease Statistics, 2017.

[4] Wang G, Zhang Z, Ayala C, Dunet D, Fang J.,George M. Costs of Hospitalization for Stroke Patients Aged 18-64 Years in the United States. J Stroke Cerebrovasc Dis. 2014 ; 23(5): 861-868.

[5] Improving Stroke Care in Greece in Terms of Management, Costs and Health Outcomes- SUN4P. Available at: http://www.sun4patients.gr/en/ (09/09/2021).

[6] Kritikou P, Spengos K, Zakopoulos N, et al. Resource utilization and costs for treatment of stroke patients in an acute stroke unit in Greece. Clin Neurol Neurosurg 2016 Mar; 142: 8-14.

[7] Gioldasis G, Taleli P, Chroni E, Daouli J, Papapetropoulos T, Elul J. In hospital direct cost of acute ischemic and hemorrhagic stroke in Greece. Acta Neurol Scand 2008. Oct; 118 (4) 268-274.

[8] Abdo R, Abboud H, Salameh P, et al. Direct Medical Cost of Hospitalization for Acute Stroke in Lebanon: A Prospective Incidence-Based Multicenter Cost-of-Illness Study. INQUIRY: The Journal of Health Care Organization, Provision, and Financing. August, 2018. 